\title{
Novel oxidative-acidic bifunctional catalyst of tungsten-phosphate modified silica-titania
}

\author{
Salasiah Che $\mathrm{Me}^{1}$, Hadi $\mathrm{Nur}^{2}$, Siew Ling Lee ${ }^{2^{*}}$ \\ ${ }^{I}$ Department of Chemistry, Faculty of Science, Universiti Teknologi Malaysia, 81310 UTM Johor Bahru, Johor, Malaysia. \\ ${ }^{2}$ Centre for Sustainable Nanomaterials, Ibnu Sina Institute for Scientific and Industrial Research, Universiti Teknologi Malaysia, 81310 UTM Johor Bahru, \\ Johor, Malaysia.
}

*Corresponding Author: sllee@ibnusina.utm.my

\section{Article history :}

Received 5 November 2015

Accepted 13 November 2015

\section{GRAPHICAL ABSTRACT}

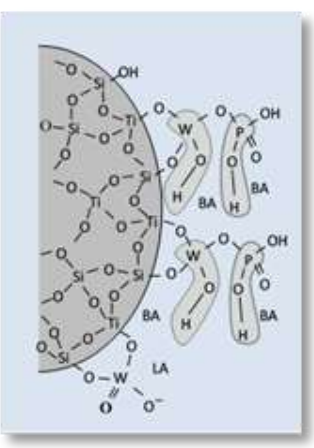

\begin{abstract}
A novel oxidative-acidic bifunctional catalyst of silica-titania supported tungsten-phosphate was successfully synthesized and characterized. Different tungsten amount was impregnated into silicatitania followed by phosphoric acid treatment via sol gel method. The impregnation of $\mathrm{WO}_{3}$ and $\mathrm{PO}_{4}{ }^{3}$ into $\mathrm{TiO}_{2}-\mathrm{SiO}_{2}$ followed by drying and calcination gave the white colour to the samples. X-ray diffractograms of the samples showed the structures of $\mathrm{TiO}_{2}-\mathrm{SiO}_{2}$ remained as amorphous structure after loading of $\mathrm{WO}_{3}$ and $\mathrm{PO}_{4}{ }^{3-}$. The catalytic performance of the samples of $\mathrm{PO}_{4}{ }^{3-} / \mathrm{xW} / \mathrm{TiO}_{2}-\mathrm{SiO}_{2},(\mathrm{x}=$ 1 and $5 \mathrm{wt} \%$ ) as bifunctional catalyst in the formation of 1,2-octanediol through conversion of 1-octene to 1,2-epoxyoctane using aqueous $\mathrm{H}_{2} \mathrm{O}_{2}$ as an oxidant was evaluated. It has been demonstrated that $\mathrm{PO}_{4}{ }^{3-} / 5 \mathrm{~W} / \mathrm{TiO}_{2}-\mathrm{SiO}_{2}$ was an active bifunctional oxidative-acidic catalyst in producing 1,2 -octanediol from 1-octene.
\end{abstract}

Keywords: bifunctional catalyst, oxidative, Brønsted acidity, tungsten oxide, phosphoric acid

(C) 2015 Penerbit UTM Press. All rights reserved http://dx.doi.org/10.11113/mjfas.v11n3.381

\section{INTRODUCTION}

Diol is a chemical compound which contains two hydroxyl groups [1]. Diols are the important chemical raw material for a wide variety of chemicals such as polyester, surfactant, and pharmaceutical raw materials and so on. Diols have a good reaction with many organic compounds such as linear and aliphatic carbon chain due to high water solubility and reactivity [2]. Linear diol consist of two primary hydroxyl groups for example in 1,2octanediol, was beneficial as an emollient, preservative, humectant and wetting agent in cosmetics and skin care products [3].

The preparation of diols is mostly carried out by two steps series which are epoxidation of olefin continued by the hydrolysis of the epoxides. In order to manufacture diols succesfully in the manufacturing industry, two reactors have to be built which give rise to the time and cost for production process. Therefore, it is highly desirable to develop the beneficial bifunctional catalyst for consecutive reaction of diol [4].

Over the past decades, the development of bifunctional catalysts has drawn researchers' attention for their potential application in consecutive reactions. In fact, a bifunctional catalyst consists of two active sites such as oxidative and acidic sites in a single material [5]. Therefore, it can be used for production of diols which are currently processed via a two-step method using two different catalysts. As the process is time-consuming and requires a high cost, a bifunctional catalyst is highly demanded to especially ensure rapid production of diols.

Recently, various oxidative-acidic bifunctional catalysts have been reported. These include niobiumphosphate impregnated silica-titania, sulfate-vanadium treated silica-titania aerogel, zirconium sulphate loaded TS1, HZSM-5 supported Mo and combination of trivalent metal ions $\left(\mathrm{Al}^{3+}, \mathrm{B}^{3+}, \mathrm{Fe}^{3+}, \mathrm{Ga}^{3+}\right)$ and titanium ion $\left(\mathrm{Ti}^{4+}\right)$ together in the framework of zeolites [4 - 7]. It was declared that presence of metal oxides such as $\mathrm{V}, \mathrm{Mo}, \mathrm{Zr}$ and $\mathrm{Nb}$ acted as redox centers had influenced formation of both Lewis and Brønsted acidity sites. Besides, it was also claimed that $\mathrm{V}$ and $\mathrm{Nb}$ acted as oxidative active sites for epoxidation $[4,5]$. Owing the similar chemical properties of tungsten to $\mathrm{Mo}$ and $\mathrm{Nb}$, it is worthy to explore the possibility usage of tungsten in a bifunctional catalyst's design.

In this work, a new bifunctional catalyst of tungstenphosphate supported on silica-titania was synthesized via 
sol-gel and impregnation methods. Their properties and catalytic activities in diol synthesis via direct conversion from alkene were presented.

\section{EXPERIMENTS}

\subsection{Catalyst Preparation}

Silica-titania was prepared via sol gel method. A mixture of tetraethylorthosilicate (TEOS, Aldrich, 99.8\%), ethanol $(\mathrm{EtOH}), \mathrm{H}_{2} \mathrm{O}$ and $\mathrm{HNO}_{3}$ was stirred at room temperature. A yellowish mixture of titanium(IV) isopropoxide (TTIP, Aldrich, 97\%), EtOH and acetylacetone was added into the previous prepared solution and stirred at room temperature, followed by drying until clear gel was obtained. The wet gel was dried overnight and calcined to yield $\mathrm{TiO}_{2}-\mathrm{SiO}_{2}$ powder [4].

In order to impregnate tungsten-phosphate on $\mathrm{TiO}_{2}-\mathrm{SiO}_{2}$ powder, ammonium tungstate (AMT) was dissolved in $0.2 \mathrm{M}_{\text {of }} \mathrm{H}_{3} \mathrm{PO}_{4}$. The wet sample of $1 \mathrm{wt} \%$ of tungsten-phosphate impregnated silica-titania was stirred vigorously for $1 \mathrm{~h}$, followed by drying overnight at $383 \mathrm{~K}$. The dry powder was calcined in a furnace at $773 \mathrm{~K}$ for $5 \mathrm{~h}$. Synthesized material was denoted as $\mathrm{PO}_{4}{ }^{3-} / \mathrm{xW} / \mathrm{TiO}_{2}-\mathrm{SiO}_{2}$, $\mathrm{x}=1$ and $5 \mathrm{wt} \%$.

For the comparison, the tungsten modified silicatitania has been prepared by dissolving AMT in water followed by impregnation with silica-titania. The sample was by drying overnight at $383 \mathrm{~K}$ and calcined in a furnace at $773 \mathrm{~K}$ for $5 \mathrm{~h}$. The samples denoted as $5 \mathrm{~W} / \mathrm{TiO}_{2}-\mathrm{SiO}_{2}$.

\subsection{Characterization}

The crystalline structure of the catalyst was determined with X-ray diffraction (XRD) recorded on a powder diffractometer (Bruker Advance D8, $40 \mathrm{kV}, 40$ $\mathrm{mA}$ ) using a $\mathrm{Cu} \mathrm{K} \alpha$ radiation source in the range of $2 \theta$ of $10-90^{\circ}$.

In order to identify the titania and tungsten species formed in the samples the data have been analyzed via Diffused reflectance UV spectra. Perkin Elmer Lambda 900 DRUV/VIS spectrometer has been used to analyze the samples under ambient condition.

On the other hand, infrared measurements were performed on a Perkin Elmer Spectrum One FT-IR spectrometer, with a spectral resolution of $2 \mathrm{~cm}^{-1}$, scan time of $10 \mathrm{~s}$ using the $\mathrm{KBr}$ pellet technique. The framework spectra were recorded in the region of $400-4000 \mathrm{~cm}^{-1}$.

\subsection{Catalytic Testing}

The bifunctional catalytic performance of the prepared materials was evaluated through the consecutive reaction of formation of 1,2-octanediol through transformation of 1,2-epoxyoctane from 1-octene. The reaction mixture consisting of $8 \mathrm{mmol}$ of 1-octene (Aldrich, 98\%), $15 \mathrm{mmol}$ of $\mathrm{H}_{2} \mathrm{O}_{2}$ in $\mathrm{H}_{2} \mathrm{O}$ (Qrec, $30 \%$ ) in $10 \mathrm{~mL}$ acetonitrile (Merck, 99.8\%) as solvent and $100 \mu \mathrm{L}$ of cyclooctane (Fluka,99\%) as an internal standard was placed in a round bottom flask equipped with a magnetic stirrer and condenser. Later, $0.05 \mathrm{~g}$ catalyst was added into the solution. The reaction was carried out in oil bath at $343 \mathrm{~K}$ for $24 \mathrm{~h}$ under stirring condition. The products of the reaction were analyzed on a HP Agilent $6890 \mathrm{~N}$ gas chromatograph using Ultra-1 column.

\section{RESULTS AND DISCUSSION}

In this study, the synthesized material $\mathrm{PO}_{4}{ }^{3-}$ $/ \mathrm{xW} / \mathrm{TiO}_{2}-\mathrm{SiO}_{2}$ with various percentage of weight of $\mathrm{WO}_{3}$ (1 and $5 \mathrm{wt} \%$ ) have been prepared by sol-gel and impregnation method. Samples $\mathrm{TiO}_{2}-\mathrm{SiO}_{2}$ and tungsten modified $\mathrm{TiO}_{2}-\mathrm{SiO}_{2}$ was synthesized for comparison purpose.

$\mathrm{TiO}_{2}-\mathrm{SiO}_{2}$ synthesized via sol gel method was light and fluffy powder after calcination at $773 \mathrm{~K}$ for $5 \mathrm{~h}$. Impregnation of $\mathrm{WO}_{3}$ and $\mathrm{PO}_{4}{ }^{3-}$ into $\mathrm{TiO}_{2}-\mathrm{SiO}_{2}$ followed by drying and calcination, the colour remain unchanged which is white fluffy powder.

The synthesized materials were analysed using Xray diffraction $(\mathrm{XRD})$ for phase identification. Figure 1 shows the XRD patterns of the samples. As can be seen, $\mathrm{TiO}_{2}-\mathrm{SiO}_{2}$ was an amorphous material. Its structure remained after loading of $\mathrm{PO}_{4}{ }^{3-}$. However, a small peak at 2 $\theta=33.5^{\circ}$ observed in the XRD patterns of $\mathrm{PO}_{4}{ }^{3-} / 1 \mathrm{~W} / \mathrm{TiO}_{2}-$ $\mathrm{SiO}_{2}$ and $\mathrm{PO}_{4}^{3-} / 5 \mathrm{~W} / \mathrm{TiO}_{2}-\mathrm{SiO}_{2}$ which was correlated to tungsten loading. No peaks corresponding to the $\mathrm{Ti}$ was detected, indicating that $\mathrm{Ti}$ was highly dispersed on the surface of $\mathrm{SiO}_{2}$, or were incorporated into $\mathrm{SiO}_{2}$ framework. The broad XRD peak at a low diffraction angle of $20^{\circ}$ to $30^{\circ}$ corresponds to the amorphous-state $\mathrm{SiO}_{2}$ shells surrounding the tungsten-phosphate. From the XRD patterns, the amorphous silica were sharper for sample $5 \mathrm{~W} / \mathrm{TiO}_{2}-\mathrm{SiO}_{2}, \mathrm{PO}_{4}{ }^{3-} / 1 \mathrm{~W} / \mathrm{TiO}_{2}-\mathrm{SiO}_{2}$ and $\mathrm{PO}_{4}{ }^{3-} / 5 \mathrm{~W} / \mathrm{TiO}_{2}-$ $\mathrm{SiO}_{2}$ compared to sample $\mathrm{TiO}_{2}-\mathrm{SiO}_{2}$. This might be due to an increase of crystallinity as a result of heat treatment. The alternative explanation for the amorphous form observed is that the $\mathrm{Ti}$ present neither in anatase nor rutile [10]. Besides, the amount of $\mathrm{PO}_{4}{ }^{3-}$ could be too little for the detection.

Figure 2 shows the UV-vis spectra of the samples. As observed, $\mathrm{TiO}_{2}-\mathrm{SiO}_{2}$ showed only a dominant peak at around $270 \mathrm{~nm}$, which is attributed to tetrahedrally coordinated Ti species. It was documented that the band at $250 \mathrm{~nm}$ was associated with tetrahedral Ti species that is widely recognized as the most important $\mathrm{Ti}$ species to provide active site for oxidation reaction. This electronic transition was assigned to a charge transfer of tetrahedral $\mathrm{Ti}$ sites between $\mathrm{O}^{2-}$ and the central $\mathrm{Ti}(\mathrm{IV})$ atom. After phosphoric acid treatment, a broad band ranged 270-320 $\mathrm{nm}$ was detected. It could be due to the presence of octahedral or polymeric Ti species in the sample. The result might suggest that transformation of some tetrahedral $\mathrm{Ti}$ framework to octahedral structure in the presence of the acid [11]. As can be seen in Figure 2, only tetrahedrally coordinated $\mathrm{Ti}$ was found in $\mathrm{PO}_{4}^{3-} / 1 \mathrm{~W} / \mathrm{TiO}_{2}-\mathrm{SiO}_{2}$. Apparently, the tetrahedral $\mathrm{Ti}$ species appeared as the 
predominant species in this sample. Meanwhile, the spectrum of $\mathrm{PO}_{4}{ }^{3-} / 5 \mathrm{~W} / \mathrm{TiO}_{2}-\mathrm{SiO}_{2}$ exhibited two bands at around 250 and $310 \mathrm{~nm}$. The loading of more tungsten seemed to increase the amount of octahedrally coordinated Ti species in the sample.

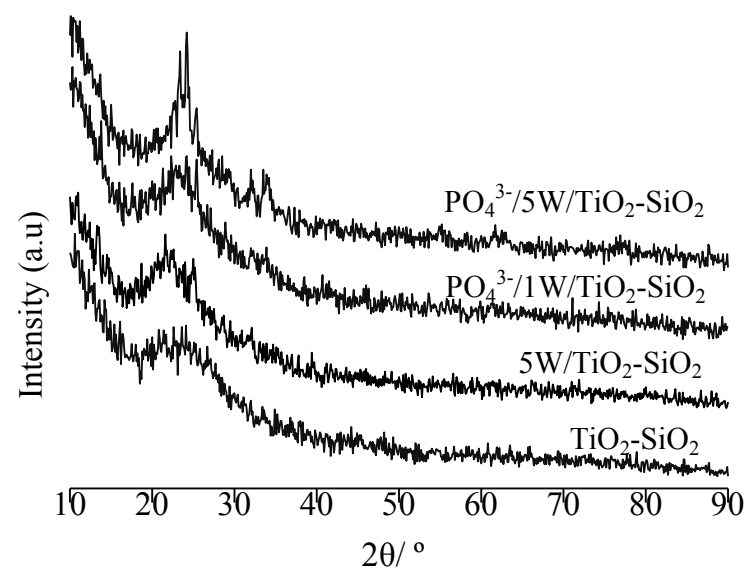

Fig. 1 X-ray diffractograms of the samples (a) $\mathrm{TiO}_{2}-\mathrm{SiO}_{2}$, (b) $5 \mathrm{~W} / \mathrm{TiO}_{2}-\mathrm{SiO}_{2}$, and (c) \& (d) $\mathrm{PO}_{4}{ }^{3-} / \mathrm{xW} / \mathrm{TiO}_{2}-\mathrm{SiO}_{2}$ (where $\mathrm{x}=1$ and $5 \mathrm{wt} \%$ )

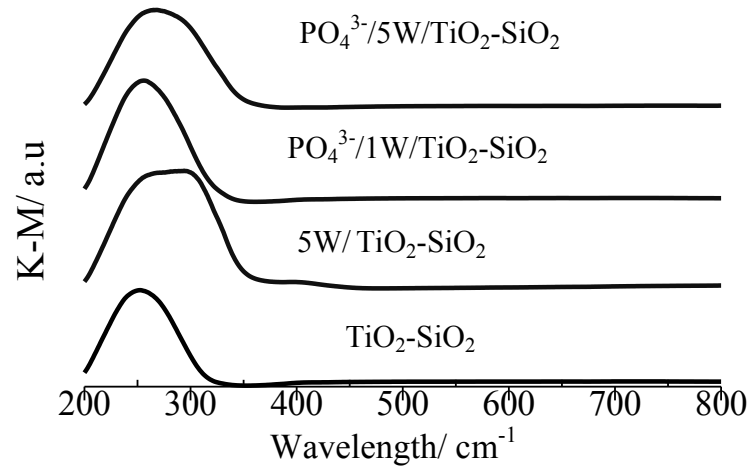

Fig. $2 \mathrm{UV}$-vis spectra of the samples $\mathrm{TiO}_{2}-\mathrm{SiO}_{2}$, tungsten modified $\mathrm{TiO}_{2}-\mathrm{SiO}_{2}$, and $\mathrm{PO}_{4}{ }^{3-} / \mathrm{xW} / \mathrm{TiO}_{2}-\mathrm{SiO}_{2}$ (where $\mathrm{x}=1$ and 5 wt $\%$ )

FTIR spectra of samples show typical silicate absorptions at $1100 \mathrm{~cm}^{-1}$, which was attributed to $\mathrm{Si}-\mathrm{O}-\mathrm{Si}$ stretching vibration [12] (Fig. 3). The band at $799 \mathrm{~cm}^{-1}$ was associated with absorptions of Si-O-Ti or Si-O-W bonds. The band at $\sim 970 \mathrm{~cm}^{-1}$ appeared as a weak shoulder in the samples, implying the $\mathrm{Si}-\mathrm{O}-\mathrm{Si}$ bonding decreased dramatically after treatment of phosphoric acid [13]. Similar finding was reported in sulphated silica-titania aerogel, another oxidative-acidic bifunctional catalyst from our previous work [7]. Besides, a broad band at $3400 \mathrm{~cm}^{-1}$ attributed to the hydroxyl $(\mathrm{OH})$ groups on the amorphous surface [14] was detected in both $\mathrm{TiO}_{2}-\mathrm{SiO}_{2}$ and $5 \mathrm{~W} / \mathrm{TiO}_{2}-$
$\mathrm{SiO}_{2}$. As observed, the band decreased significantly after the phosphoric acid treatment. This phenomenon could be a good indication for the attachment of the phosphate at the hydroxyl groups, leading to the reduction in the band intensity of the $\mathrm{OH}$ groups.

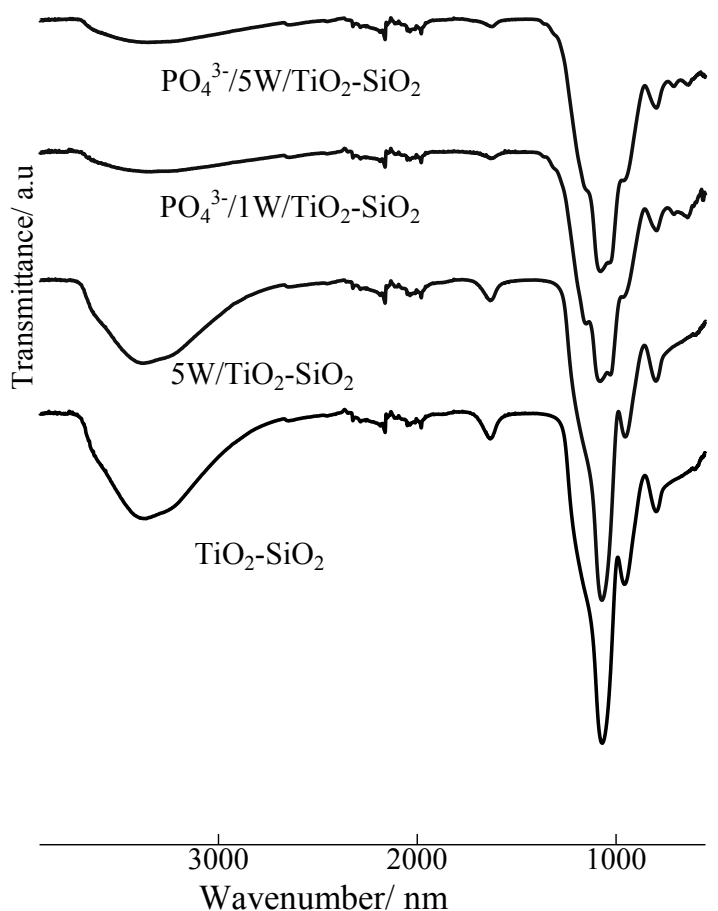

Fig. 3 FTIR spectra of the samples $\mathrm{TiO}_{2}-\mathrm{SiO}_{2}, 5 \mathrm{~W} / \mathrm{TiO}_{2}-\mathrm{SiO}_{2}$, and $\mathrm{PO}_{4}{ }^{3-} / \mathrm{xW} / \mathrm{TiO}_{2}-\mathrm{SiO}_{2}$ (where $\mathrm{x}=1$ and $5 \mathrm{wt} \%$ )

The catalytic performance of the samples was tested through consecutive transformation of 1 -octene to 1,2octanediol through the formation of 1,2-epoxyoctane using aqueous hydrogen peroxide at $343 \mathrm{~K}$ for $24 \mathrm{~h}$. As depicted in Table 1, negligible 1,2-epoxyoctane was detected using $\mathrm{TiO}_{2}-\mathrm{SiO}_{2}$, implying $\mathrm{Ti}$ species acted as weak oxidative site for the epoxy formation. This sample was inactive in 1,2-octanediol production. After loading of $5 \mathrm{wt} \%$ of tungsten, the yield of 1,2-epoxyoctane increased 2 folds similarly no diol was detected in the reaction. Meanwhile in the $\mathrm{PO}_{4}{ }^{3-} / 1 \mathrm{~W} / \mathrm{TiO}_{2}-\mathrm{SiO}_{2}$ catalyst the production of 1,2epoxyoctane has been decreased and no diol production. It was observed that $\mathrm{PO}_{4}{ }^{3-} / 5 \mathrm{~W} / \mathrm{TiO}_{2}-\mathrm{SiO}_{2}$ catalyst has produced $0.186 \mathrm{mmol}$ of 1,2-epoxyoctane and $0.854 \mathrm{mmol}$ of 1,2-octanediol, indicating $\mathrm{PO}_{4}{ }^{3-} / 5 \mathrm{~W} / \mathrm{TiO}_{2}-\mathrm{SiO}_{2}$ was a bifunctional catalyst to produce diol from alkene via single step reaction. 
Table 1 Product yields of $\mathrm{TiO}_{2}-\mathrm{SiO}_{2}, 5 \mathrm{~W} / \mathrm{TiO}_{2}-\mathrm{SiO}_{2}$, and $\mathrm{PO}_{4}{ }^{3-}$ $/ \mathrm{xW} / \mathrm{TiO}_{2}-\mathrm{SiO}_{2}$ (where $\mathrm{x}=1$ and $5 \mathrm{wt} \%$ )

\begin{tabular}{lcc}
\hline \multicolumn{1}{c}{ Catalyst } & $\begin{array}{c}\text { 1,2-epoxyoctane } \\
\text { (mmol) }\end{array}$ & $\begin{array}{c}\text { 1,2-octanediol } \\
\text { (mmol) }\end{array}$ \\
\hline $\mathrm{TiO}_{2}-\mathrm{SiO}_{2}$ & 0.136 & 0 \\
$5 \mathrm{~W} / \mathrm{TiO}_{2}-\mathrm{SiO}_{2}$ & 0.296 & 0 \\
$\mathrm{PO}_{4}{ }^{3-} / 1 \mathrm{~W} / \mathrm{TiO}_{2}-\mathrm{SiO}_{2}$ & 0.165 & 0 \\
$\mathrm{PO}_{4}{ }^{3-} / 5 \mathrm{~W} / \mathrm{TiO}_{2}-\mathrm{SiO}_{2}$ & 0.186 & 0.854 \\
\hline
\end{tabular}

\section{CONCLUSION}

In this research, the synthesis and characterization of tungsten oxide and phosphoric acid impregnated silicatitania have been carried out. Both tetrahedrally and octahedrally coordinated $\mathrm{Ti}$ species were detected in phosphoric acid and tungsten oxide modified $\mathrm{TiO}_{2}-\mathrm{SiO}_{2}$. Presence of tungsten oxide and phosphate was verified via XRD and FTIR analyses, respectively. The formation of 1,2-octanediol through conversion of 1-octene to 1,2epoxyoctane was conducted to evaluate the catalytic activity of oxidative-acidic bifunctional catalyst. Material $\mathrm{PO}_{4}{ }^{3-} / 5 \mathrm{~W} / \mathrm{TiO}_{2}-\mathrm{SiO}_{2}$ is an active bifunctional oxidativeacidic catalyst in producing 1,2-octanediol from 1-octene.

\section{ACKNOWLEDGEMENTS}

This work was supported by Ministry of Higher Education (MOHE) for Fundamental Research Grant Scheme (R.J130000.7809.4F527) and Universiti Teknologi Malaysia for the Research University Grant (Q.J130000.2609.10J66).

\section{REFERENCES}

[1] J. March, Advanced Organic Chemistry: Reactions, Mechanisms, and Structure, third ed., Wiley, New York, 1985

[2] D.A Brown, A. A. Khorlin, K. Lesiak, W. Y. Ren, U.S. Patent. 6623724. 2003.

[3] R. Mildbradt, S. Klein, F. X. Scherl, E. Gatter A. Oberhauser, U.S Patent 6881399. 2005.

[4] J. M. Ekhsan, S. L Ling, H. Nur, Appl. Catal. A: Gen. 471 (2014) 142.

[5] L. S. Lee, S. C. Wei, H. Nur, H. Hamdan, Int. J. Chem. Reactor. Eng. 8 (2011) 1.

[6] C. A. Muller, M. Schneider, T. Mallat, A. Baiker, Appl. Catal A: Gen. 201 (2000) 253.

[7] L. S. Ling, H. Hamdan, J. Non-Cryst. Solids. 354 (2008) 3939.

[8] D. Prasetyoko, Z. Ramli, S. Endud, H. Nur, J. Mol. Catal. A: Chem. $241(2005) 118$.

[9] L. S. Lee, H. Nur, H. Hamdan, Catal. Lett. 132 (2009) 28.

[10] S. Hu, R.J. Willey, B. Notari, J. Catal. 220 (2003) 240.

[11] D. Prasetyoko, Z. Ramli, S. Endud, H. Nur, Mater. Chem. Phys. 93 (2005) 443

[12] M.C. Capel-Sanchez, J.M. Campos-Martin, J.L.G. Fierro, Appl. Catal. A 246 (2003) 69

[13] D. Prasetyoko, Z. Ramli, S. Endud, H. Nur, Adv. Mater. Sci. Eng. 2008 (2008) 1.

[14] M. Tanaka, H. Shima, T. Yokoi, T. Tatsumi, J.N. Kondo, Catal. Lett. 141 (2011) 283 